\title{
Developing College Students' Service Consciousness to Serve the Development of Local Economy: Based on Colleges in Guangxi
}

\author{
Chen Lingping \\ Office of Educational Administration \\ Institute of Information Technology of GUET \\ Guilin, China \\ chenlp@guet.edu.cn
}

\author{
Lingxiqin \\ Associate Dean of Education \\ Institute of Information Technology of GUET \\ Guilin, China \\ Lxqin@guet.edu.cn
}

\begin{abstract}
One of the purposes of higher education is to develop qualified personnel to serve the development of local economy. Therefore, college students' service consciousness should be cultivated so as to achieve this goal. It is the need of the advance of local economy and society, the further development of higher education institutions, especially the quality expanding and the sound personality development for college students. The cultivation of students' service consciousness should be carried out in the whole process of higher education and more positive changes should be sought in education mode, teaching plan and internship.
\end{abstract}

Keywords- the development of local economy, higher education, college students, service consciousness

\section{INTRODUCTION (HEADING 1)}

Bring prosperity to Guangxi people, enhance overall strength of Guangxi and make leap-forward development. This strategic task, reflecting the essential requirement of Scientific Outlook on Development and the strong desire of the people of all ethnic groups of Guangxi, is the inevitable choice when Guangxi enters into a new period. The development and opening up of Beibu Gulf Economic Zone is a new challenge and chance for the colleges of Guangxi. Training the qualified personnel, technological innovation and social service are the three roles of universities. Among them , training the qualified personnel for the local economic development, especially development of the service consciousness of the personnel, should be given the top priority. In modern society, the personnel without service consciousness are not qualified. Without the strong service consciousness, the personnel will not throw themselves into the social practice. They cannot make full use of their capabilities and expertise either. Faced with new situation , therefore, colleges in Guangxi should attach importance to developing students' service consciousness .

\section{THE DEFINITION OF MODERN SERVICE AND SERVICE CONSCIOUSNESS}

The so-called service means working for interests of the collectives, others or some cause; or the behavior, process and result which satisfy other people's expectation or demand. Service consciousness refers to the service behavior which are voluntary, self-conscious and initiative .
People used to define "service" as a derogatory term , with the meaning of waiting on, being a lackey, being a maid. The service providers often refer to the waiters, waitresses, servants, who have no dignity and are inferior to other people. They are in humble position and are absolutely obedient and passive. Therefore, they are not equal with those who are served. The served are superior to the service providers. The completely new definition of "service" is "serving the people" which was given by Chairman Mao Zedong on a memorial ceremony held for the soldier Zhang Side in 1944. Hence, "serving the people" not only became the creed followed by the Communist Party of China(CPC) and the members of CPC but also was written into the Constitution in order to make "serving the people" the legal obligation which must be met by the state organs and its work personnel.

"Service" is given more meanings in modern society, such as public servants, after-sale service, technical support, volunteers, and so on. Besides, the service concept is being continually renewed, for example, management is service, education is service and technology is service. The Central Committee and the State Council increased emphasis on the necessity of building a service-oriented government. It can be clearly seen that modern service should be mutual and equal. The service consciousness of the people today should be voluntary, self-conscious and initiative. When people are serving others, they enjoy the service from others. Furthermore, those who have strong service consciousness and good service will win the trust, the market and the respect. The third article of the Constitution stipulates that the state trains specialized personnel in all fields who serve socialism, expands the ranks of intellectuals and creates conditions to give full scope to their role in socialist modernization. The Constitution clarifies that the personnel trained by the state must serve socialism. As a result, the college students should have good service consciousness as well as excellent professional knowledge.

\section{PERSONNEL WITH STRONG SERVICE CONSCIOUSNESS NEEDED FOR THE LOCAL ECONOMIC DEVELOPMENT}

A. The demand of local economic development

Guangxi, in the underdeveloped ethnic minorities areas 
of the west, remains comparatively underdeveloped in economic and social development. The environment is harsh for a new business and development. In such an area, college students without utter devotion spirit and service consciousness will not settle down and serve on the new development of Guangxi. A great opportunity is provided for the colleges to serve the society with the development and opening up of Beibu Gulf Economic Zone. With the strategic tasks of developing large scale industry, big port, transport, logistics, metropolis, tourism, investment and culture in Beibu Gulf Economic Zone, the higher education must adapt to the economy society and promote each other and serve the development and opening of Beibu Gulf Economic Zone. The colleges should change the standards of personnel. Focusing on the theme of enriching the people , building up Guangxi and making leap-forward development and serving the new development of Guangxi , the colleges must attach importance to training students to acquire professional knowledge and making effort to develop students' service consciousness.

\section{B. The demand of modern scientific management}

In modern society, "Management is service" is not a slogan any more. The product designers, the producers and sellers need to have service consciousness; the administrators in all fields need to have service consciousness; the civil servants in government organs need to have more service consciousness. In the report on the work of the government delivered at the Third Session of the Eleventh National People's Congress, when talking about building up a serviceoriented government with which the people are satisfied, Premier Wen Jiabao pointed out that "we will fully and properly perform government functions and attach greater importance to public services and administration. We will quickly improve the public service system with full coverage for all, and comprehensively improve our ability to provide basic public services." And in the report on the work of the government delivered at the fourth Session of the Eleventh National People's Congress, Premier Wen Jiabao emphasized that "Governments at all levels need to work hard to accomplish practical results for the people; and all public servants should genuinely become servants of the people."

Therefore, in order to enhance the management performance, gain the trust and support of the people, the administrators in the government offices and enterprise and public institutions are required to possess basic concept and method and the good service consciousness. A large number of management personnel with strong service consciousness are in demand for the development of Guangxi. As a result, the college students who take the position of management must refresh service concept, go deep into the realities of life, go down to the primary level, be aware of the facts, handle concrete affairs, solve the problems concerned by the people, and make sure to provide initiative service, sincere service and quality service. Hence, they can become genuine civil servants with whom the people are satisfied.

\section{The demand of college self-progress and self- development}

The colleges, which take the initiative in serving on the development and opening up of Beibu Gulf Economic Zone, take up their responsibility of high education and do work according to the education law consciously. Meanwhile, the development and opening up of Beibu Gulf Economic Zone and the development of economic society of Guangxi will definitely improve the development of higher education and give a powerful impetus to the reform and innovation of higher education. Whether the personnel trained by colleges are accepted by the society and the employers will reflect teaching quality and schooling level and influence directly the existence and development of colleges

Colleges in Guangxi should focus on the theme of serving the new development of Guangxi and get fully aware of the opportunity and challenge facing Guangxi economic and social development. The colleges should also take the initiative in adapting to and serving the economic and social development of Guangxi, especially the development and opening up of Beibu Gulf Economic Zone. New changes and development should be explored in the aspects of education philosophy, personnel training mode, discipline and specialty structure, teaching contents and methods, ranks of teachers, scientific research and technological development. Education quality should be improved in order to train the students to become the modern personnel with both the great theoretical knowledge and practical ability and good service awareness.

\section{The demand of college students quality development and right personality development}

Professional knowledge has been paid more attention to in higher education, while the comprehensive qualities are ignored, such as cooperation ability, professional dedication, spirit of utter devotion and service consciousness. Service consciousness and devotion are indispensible quality and personality for the modern personnel. No matter how much knowledge and technology he acquires, a person cannot be successful if he is alienated from society and doesn't serve the people. As a matter of fact, the people who lay emphasis on professional knowledge and neglect humanistic quality, the people who always ask for something and never dedicate themselves to anything and the people who only enjoy others' service and never serve or take care of others, do not have right personality. Such people would not be popular in the modern society and are not likely to succeed. Only when the college students apply their knowledge and technology to serving the people and society, can they amount to something and make contribution to the society and the people. 


\section{DEVELOPING COLLEGE STUDENTS’ MODERN SERVICE CONSCIOUSNESS}

\section{A. Strengthening the training on campus and improving students' service consciousness}

The education and development of service consciousness of college students must run through the whole process of learning. First, the training plan and teaching plan should conform to the society's requirement of the personnel quality. Service course can be integrated with the major courses and modern service knowledge added to the curriculum system. In this way, the students can acquire the knowledge of service systematically and understand the service and etiquette norm. Secondly, in the teaching process, the teachers can instill the students with modern service philosophy and combine the professional knowledge acquisition with serving the society, serving the companies and serving the people. Finally, the students are offered the practice opportunity to foster service consciousness in the college culture development and the activities of clubs. The students' cooperation consciousness , gratitude consciousness, service consciousness, and spirit of utter devotion are developed in mimic classroom and mimic community and voluntary practice at school. The acquisition of professional knowledge and training of service consciousness are promoted mutually; gratitude education is integrated with fostering spirit of devotion; IQ education is combined with EQ education.

\section{B. Stimulating service enthusiasm in the social investigation and practice}

Social investigation and practice are import means for the college students to get to know the society and the country and the autonomous region. They are also principal channels to apply theoretical knowledge, foster spirit of devotion, strengthen service consciousness. Growing up in the families and campus, the college students are more likely to be alienated from society, and divorced from reality and the masses. Some students regard what they learn today as the capital they will use to ask for something in the future. They do not intend to repay the society and serve the people. Only when they go out of the classrooms, go deep to the society, go to the reality, get ride of the sense of superiority of being an unusually lucky person , try to be close to the people, really set up the idea of serving the people wholeheartedly and consciously and actively work for the interests of the people, can they achieve unity of the personal value and social value.

Beibu Gulf Economic Zone provides the students a stage to do an internship and practical work. Through the various activities of social investigation and practice, the colleges students' professional quality can be developed, the service consciousness can be developed and the students' ability to find employment and start their own business can be enhanced too. The activities can not only help the students grow and succeed and stimulate their service enthusiasm, but also give them the chance to nurture their employability and entrepreneurial abilities. Meanwhile, the local economy and culture development can be promoted actively.

\section{Being the volunteers to serve others and make contribution to society}

Volunteers' activities are the social work which the volunteers aim to do to serve other people. College volunteers can not only provide help for people, make contribution to the society, but also apply the knowledge and skill to the practice and accept the test. It is a good opportunity to acquire new knowledge and skills, enhance ability and broaden horizon. Volunteers' work can help to meet the need of self fulfillment, increase the sense of social responsibility, develop service consciousness from within and set up correct values and outlook on life.

The college students put service philosophy in practice by serving temporary position in the countryside, taking the post to support agriculture and working as village officials in the holidays or after graduation. The countryside serves as a stage for the college students to display their ability and a school to experience life. To the college students, they can develop a close bond with the masses and enrich life experience by going to the level and the countryside to provide public service, production service, life service and rescue service. They can also apply the technology they mastered to the countryside construction to serve the people in the countryside actively and the economic society of the countryside, in the aspects of improving the country infrastructure, and the production and life condition, solving the problems the masses are concerned. By the activities, the students not only serve the society but also accumulate spirit wealth which is useful in their life.

\section{REFERENCES}

[1] Wen Jiabao . Report on the work of the government delivered at the Fourth Session of the Eleventh National People's Congress [EB/OL]. Retrieve from http://news.sina.com.cn/c/2011-0305/105922057880.shtml

[2] Wen Jiabao . Report on the work of the government delivered at the Third Session of the Eleventh National People's Congress [EB/OL] . Retrieve from http://www.gov.cn/2010lh/content_1555767.htm

[3] Jin Zhengyi, “ On the Basic Attributes of Public Service-orient Government,” Public Administration and Law, vol 124, pp. 1-5, December 2008.

[4] Liu Ke, "Strengthening and Promoting Service, Building a Harmonious Society", Journal of Xi'an University of Posts and Telecommunications, vol 14 , pp. 151-153, April 2009.

[5] He Hongxia, “On University Volunteer Community Service”, Journal of Shanxi Youth Vocational College, vol 86, pp. 56-59, Januanry 2009. 